\title{
New visualization agents to reveal the hidden secrets of latent fingerprints
}

\author{
Aayush Dhunna, Shefali Anand, Anjali Aggarwal, Abhishek Agarwal, Priyanka Verma* (D) and Uttam Singh
}

\begin{abstract}
Background: Forensic scientists have exposed number of ways for recovering usable finger marks that divulge the identity of the person involved or linked to the felony. Numerous incremental progresses were made over decades by introducing different powder formulations for development of latent fingerprints which overcome the use of chemicals which are toxic and pose potential health jeopardies.

Result: In the present study, a less expensive, simple and easily accessible household materials such as cumin, Coriander powder, coriander, turmeric, black pepper, etc. have been used to disclose the mysteries of latent fingerprints on an aluminum foil by dusting method which gives good results. The best results were shown by limestone and Fuller's earth.
\end{abstract}

Conclusions: Our original study has come up with more of such novel and innovative dusting powders that has shown momentous outcomes with the metal substrate. This type of work has not been reported previously and can provide beneficial information to the sleuths in cases of dearth or non-availability of orthodox fingerprint development powders and chemicals.

Keywords: Latent fingerprints, fuller's earth, Limestone, Household products, Powder dusting method, Turmeric

\section{Background}

Fingerprints are considered as one of the most imperative piece of physical evidence for unraveling majority of civil and criminal cases, as fingerprint individuality is highly admissible in the court of law. The most common type of fingerprint found at crime scene is Latent Fingerprint which is left unobserved by the perpetrator. The adoption of method for developing latent fingerprints solely depends on the type of surface, efficiency and simplicity. Latent Fingerprints can be discovered by various methods. Earlier, powder dusting methods including black powder (Haque et al. 1989), fluorescent powders (Kerr et al. 2013), and other synthetic food and festive colors (gulal) (Kumari et al. 2011), ninhydrin dipping (Crown 1969), iodine fuming (Jasuja et al. 2012) and silver nitrate (Dalrymple et al. 1977) were most commonly employed for the development of such prints. These techniques exhibited quite effective results for many surfaces but to increase their efficiency and to simultaneously diminution the price, some advances were

\footnotetext{
* Correspondence: priyankakverma25@gmail.com

Forensic Science, UIAHS, Chandigarh University, Mohali, India
}

needed. Traditional used powders, bears noxious constituents and pose potential health risks. The most common method implied to disentangle the secrets of latent prints is "Powder Dusting Method". The mechanism of how the fingerprint powder works is explained as: Firstly, the affected area is located then the fingerprint powder is sprinkled over the affected area. The powder adheres to the oils and other constituents of the sweat left in a fingerprint and the print is deciphered. But sometimes only partial or incomplete prints are deciphered. And also sometimes the powders do not give contrast which makes it difficult for the examiner to study and compare the developed prints. To overcome this disadvantage, in this study attempts have been done to develop latent fingerprints using powders which are non-toxic and easily available. The powders used in this study are household products which have so many medicinal uses also.

\section{Turmeric}

It is a mixture of phenolic compounds which is called as curcumin and also a volatile oil which contains zingiberene and turmerone (Pandey BP 2003); other 
monoterpenes and cineole; starch; protein; and high amounts of vitamin A. Gall bladder showed stimulating effects on action of these essential oils. More bile is produced by stimulation through these oils which also help in regulating viscosity in the liver (Figs. 1 and 2).

\section{Cumin powder (cumin)}

The presence of a volatile oil in cumin powder (Fig. 3): cumin aldehyde results in strong aromatic smell. Cumin fruits are warm and have bitter taste due to cumin aldehyde which exists in the cumin fruits in the proportion $(2.5-4) \%$. The method of separation of fruit used is distillation with water. Pale yellow colour is characteristic and composed of a mixture of cymene or cymol and cyminol or cuminic aldehyde (Fig. 4). The above mentioned are its chief constituent. Aldehydes that are present in the oil are responsible for the characteristic odor of cumin.

\section{Garam masala}

The ingredients differ by region and also according to each individual preferences. In powdered form Garam masala basically consists of CUMIN, CORIANDER, BLACK PEPPER, CARDAMOM, and CINNAMON. In this research work, MDH Garam masala (Fig. 5) has been used for development of latent fingerprints.

\section{Limestone}

Calcium carbonate is the basic contituent of Limestone (Fig. 6). Limestone is composed of nearly $50 \%$ of carbonate minerals, generally consisting the mineral dolomite (calcium-magnesium carbonate, $\mathrm{CaMg}\left[\mathrm{CO}_{3}\right]_{2}$ ) or calcite (pure $\mathrm{CaCO}_{3}$ ) or even both.

\section{Gram flour}

The chemical formula of Gram flour or wheat flour is $\left(\mathrm{C}_{6} \mathrm{H}_{10} \mathrm{O}_{5}\right) \mathrm{n}$. It is composed of starches in its polymer form. Starch is a carbohydrate which can be further categorized as an amylase also. The bran and the germ are included in wheat kernel from which the Whole-wheat flour is derived. Color of the wheat flour is brown, and has a nutty flavor. In cooking, whole-wheat flour is used to produce a denser result. Which is result of its thickening abilities.

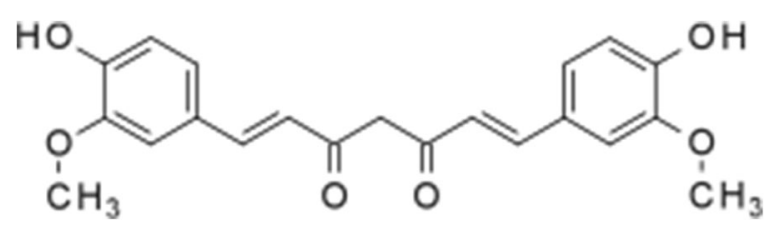

Fig. 1 Chemical structure of Curcumin keto form

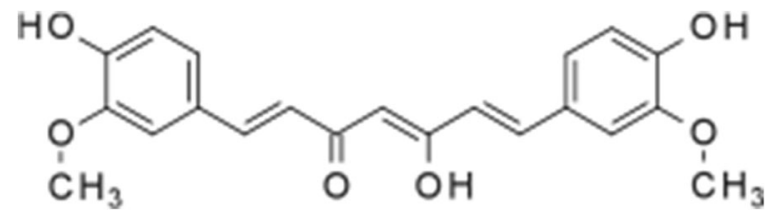

Fig. 2 Chemical structure of Curcumin enol form

\section{Coriander powder}

Coriander leaves gives aroma which is also the result of presence of aldehyde compounds. The largest proportion of these are those aldehydes which have 6-10 carbon atoms. Particularly decyl (10) and nonyl (9) aldehyde. Other major constituents of the leaves are 2-decenoic acid and decanoid acid and tetradecanoid acid. The chemical composition of coriander is slightly different from its main constituent that is Linalool (Fig. 7).

\section{Materials and methodology}

In the present study, the latent finger/ thumb impressions of 100 individuals (both male and females) were collected with variable donor capabilities on non-porous metallic substrate i.e., aluminium foil. Powder dusting method is used to develop latent fingerprints in this study. For development of latent fingerprints, different powders were used. A few grams of commercially available kitchen products (fine blended powders) like turmeric powder (haldi), red chilli powder (lalmirch), cumin powder (cumin), kitchen king masala, lime stone powder (chuna), coriander powder, garam masala powder, gram flour were taken. These powders were individually stored in glass bottles and sealed. The research work was carried out in the month of November when the variation in temperature was from $15^{\circ}$ to $25^{\circ}$ with relative humidity ranging between $50 \%$ to $68 \%$. For successful developments, powder was applied to a surface by sprinkling powder with the help of brush and lifting the developed prints with help of tapping method. As powder was brushed over an area containing a latent print, particles adhere to greasy deposits. Only ridge patterns stand out from the contrasting background. After waiting for a fraction of seconds, excess of powders adhering to the prints were dusted off to visualize clear prints. Comparative analysis was done for

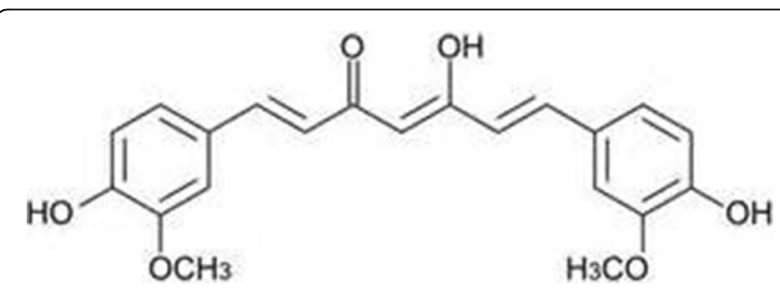

Fig. 3 Chemical structure of Cumin powder 


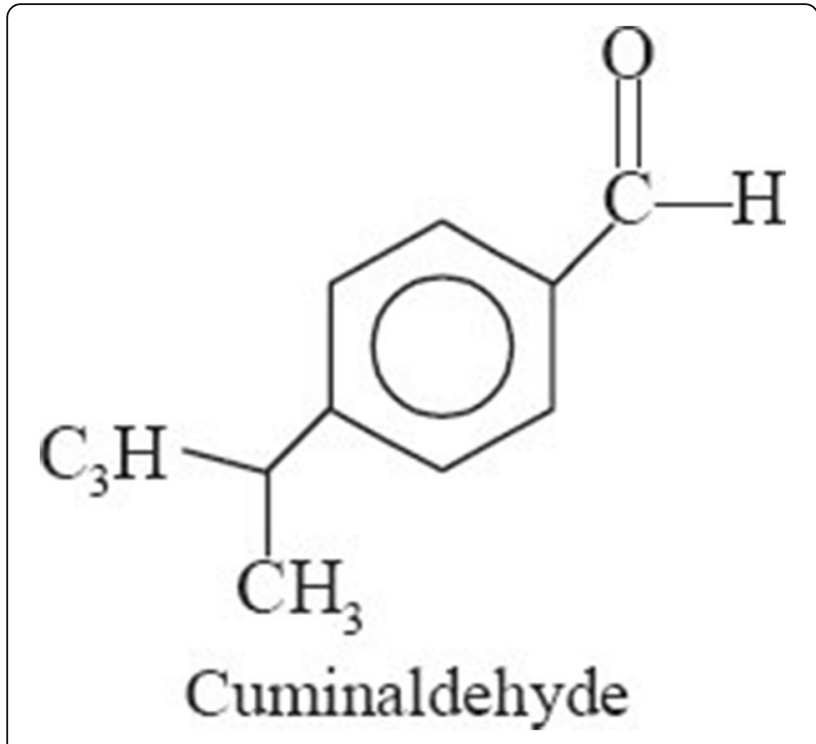

Fig. 4 Chemical structure of Cuminaldehyde

the powders to check for the best results obtained on the selected substratum (Aluminum foil).

\section{Results and discussion}

The results of the present study using different commercially available kitchen product powders on aluminum foil (metal) are shown in Figs. 8, 9, 10, 11, 12, 13, 14, 15, 16. The appraisal after comparing results of different powders on aluminum foil substrate divulges that better results (clear ridges) were observed with Limestone, Gram flour, Fuller's earth Powders, partial identifiable ridge pattern by turmeric, Cumin, Red Chilli and less identifiable by Garam Masala Kitchen King, Coriander powder respectively.

Limestone: Presence of calcite and dolomite in Limestone Powder makes the prints identifiable. Similar attempts has been made (Singh et al. 2013) using silica gel

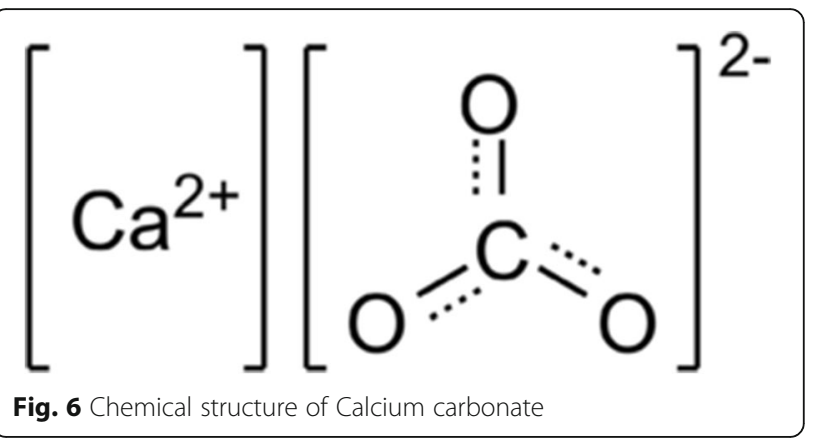

G on different substrates including aluminum foil and have got successful results.

Gram flour Powder:-Amylase being an important component of the gram flour powder combines with the fat component of the fingerprints, thereby indicating clear ridge characteristics.

Turmeric Powder: - The turmeric powder adheres to the latent fingermarks which is the result of hydrogen bonds forming between the hydroxyl and carbonyl group of the curcumin and the fatty acids/glycerides of sebum, which comprises the turmeric powder (Garg 2011).

Reaction of thymol and cuminic aldehyde in the Cumin Powder with the glycerides of sebum produces partial identifiable prints.

Prints obtained using Kitchen Powders like Garam Masala, kitchen King, Coriander Powder were very less identifiable because of the less adherence properties of the major components of the powders to the sebaceous secretions.

These results from the study suggested that commercially available kitchen product powders can successfully be used on Limestone, Fuller's earth on aluminum foil surfaces except garam Masala, Kitchen King, and Coriander powder. The present a Cumin:

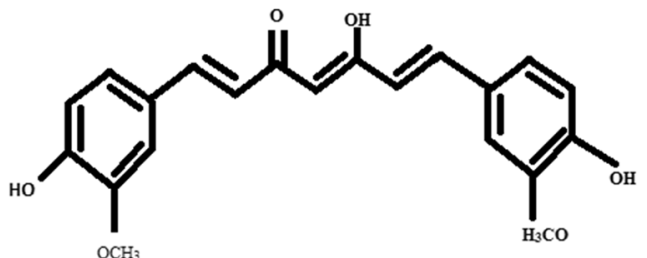

C Black pepper: Structure of piperine

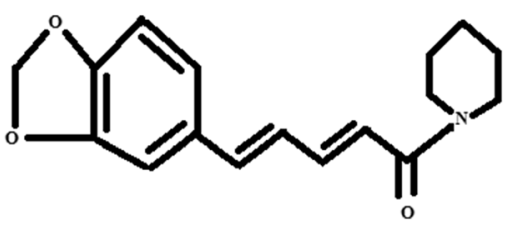

b Coriander

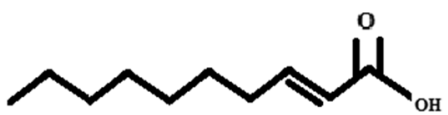

2-DECENOIC ACID

d

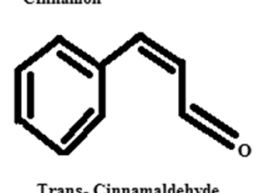

Fig. 5 Ingredients involved in Garam Masala 


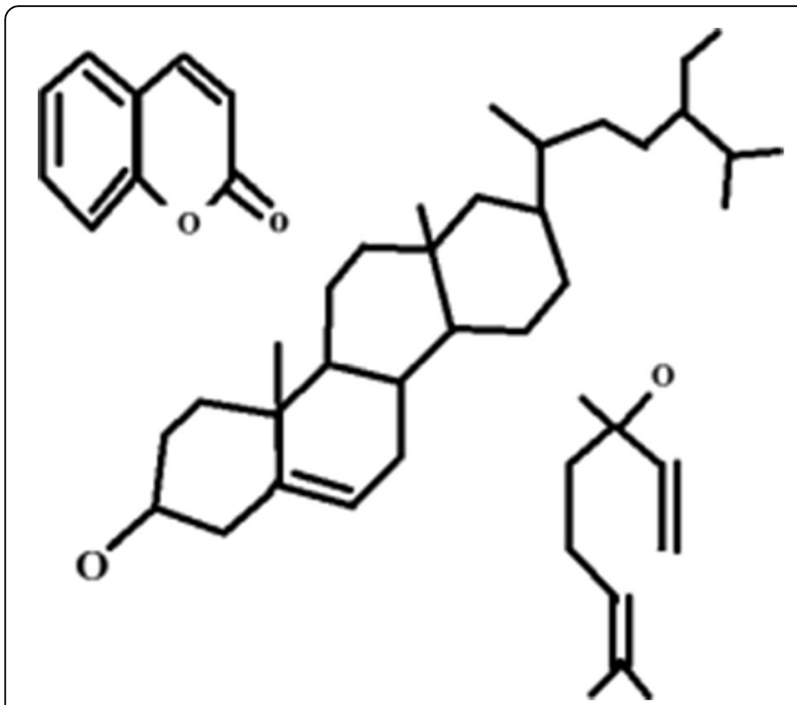

Fig. 7 Chemical structure of Coriander and Linalool

study is the preliminary stage and can also be explored further in relation to time, humidity and other factors. Similar attempts have been made on other agents, such as gulaal (Kumari et al. 2011) food colours (Kumari et al. 2011), for the developing latent fingerprints.

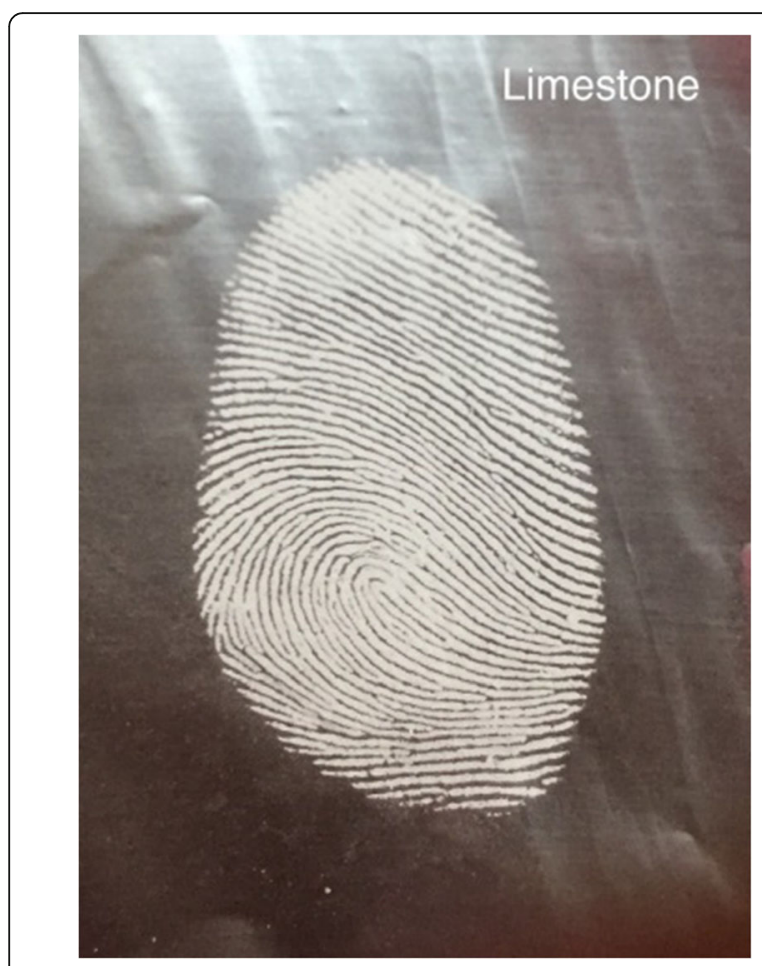

Fig. 8 Development of Latent fingerprint by Limestone powder on Aluminum Foil

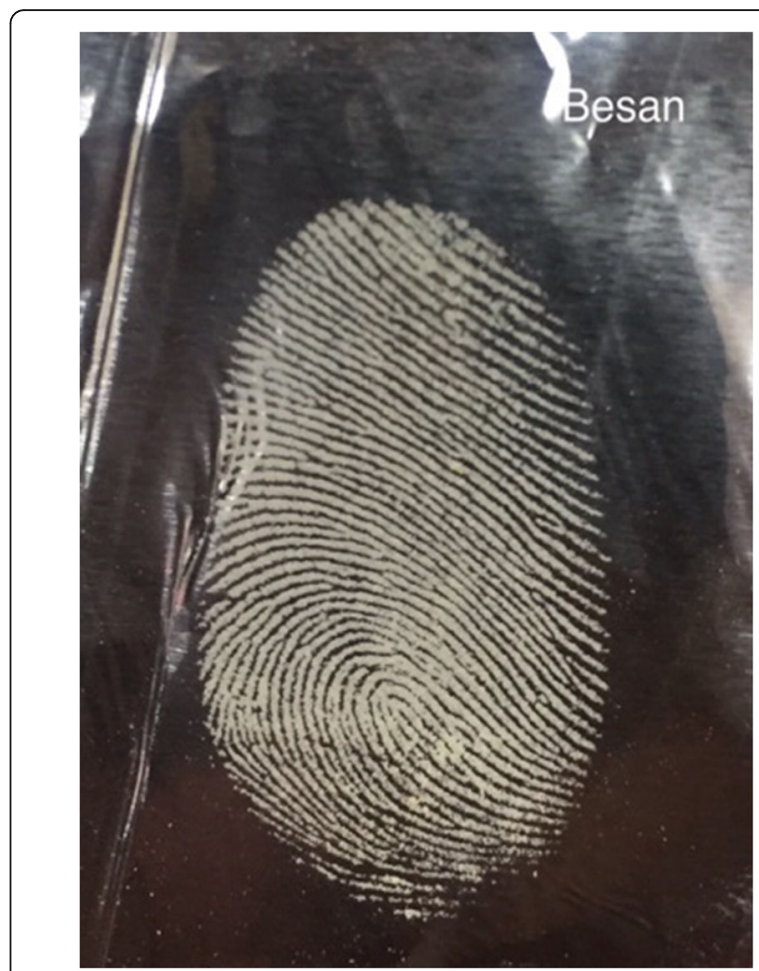

Fig. 9 Development of Latent fingerprint by Gram flour powder on Aluminum Foil

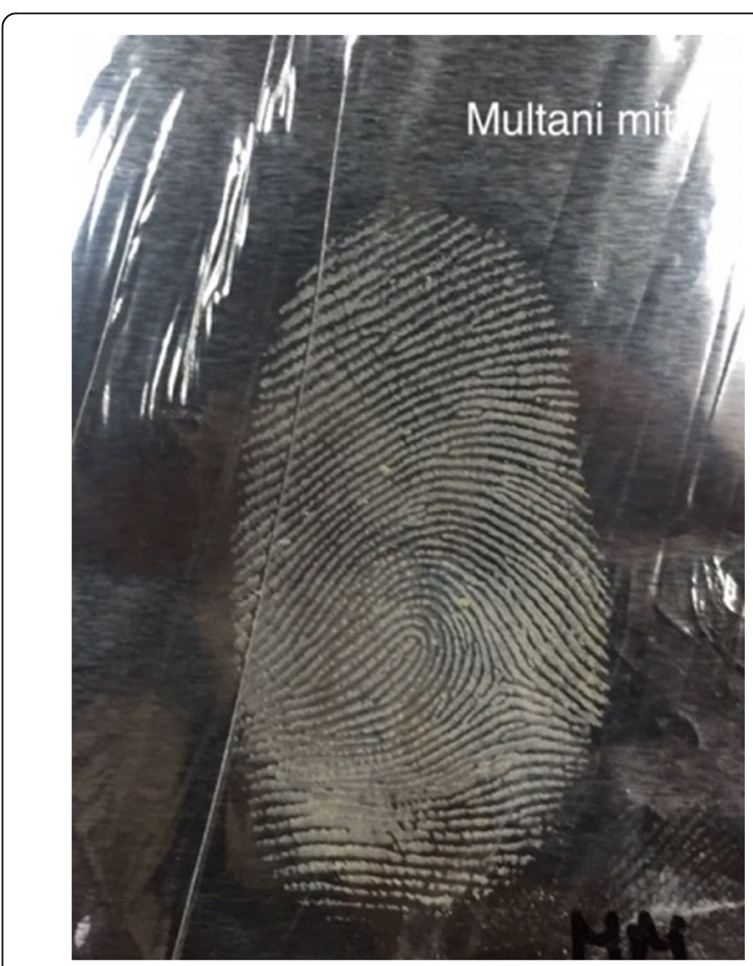

Fig. 10 Development of Latent fingerprint by Fuller's earth powder on Aluminum Foil 


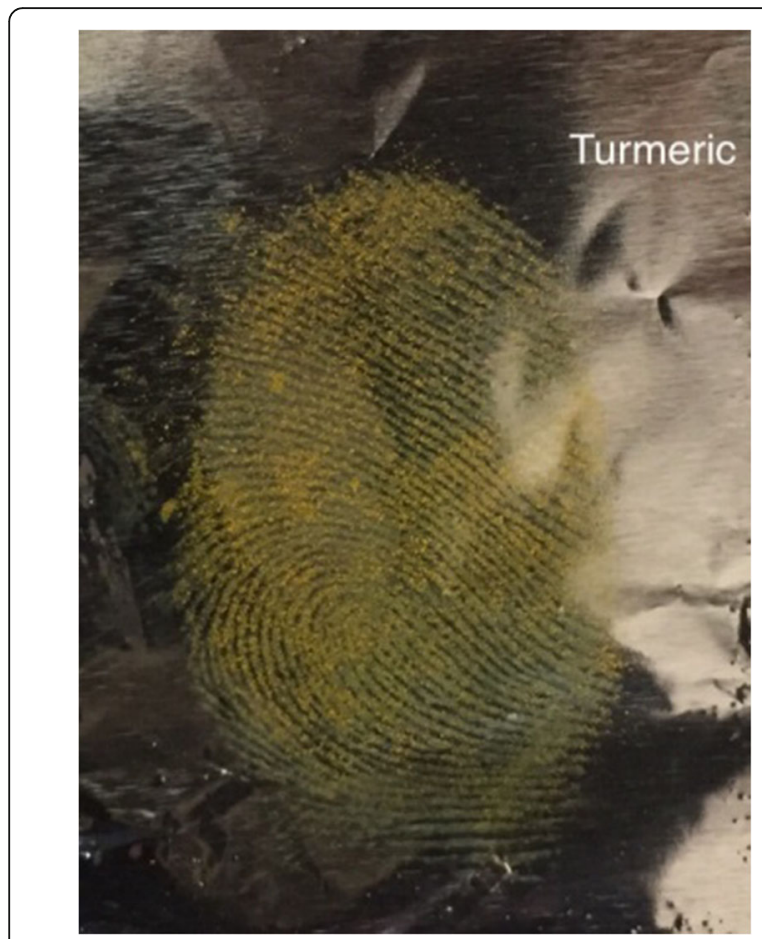

Fig. 11 Development of Latent fingerprint by Turmeric powder on Aluminum Foil

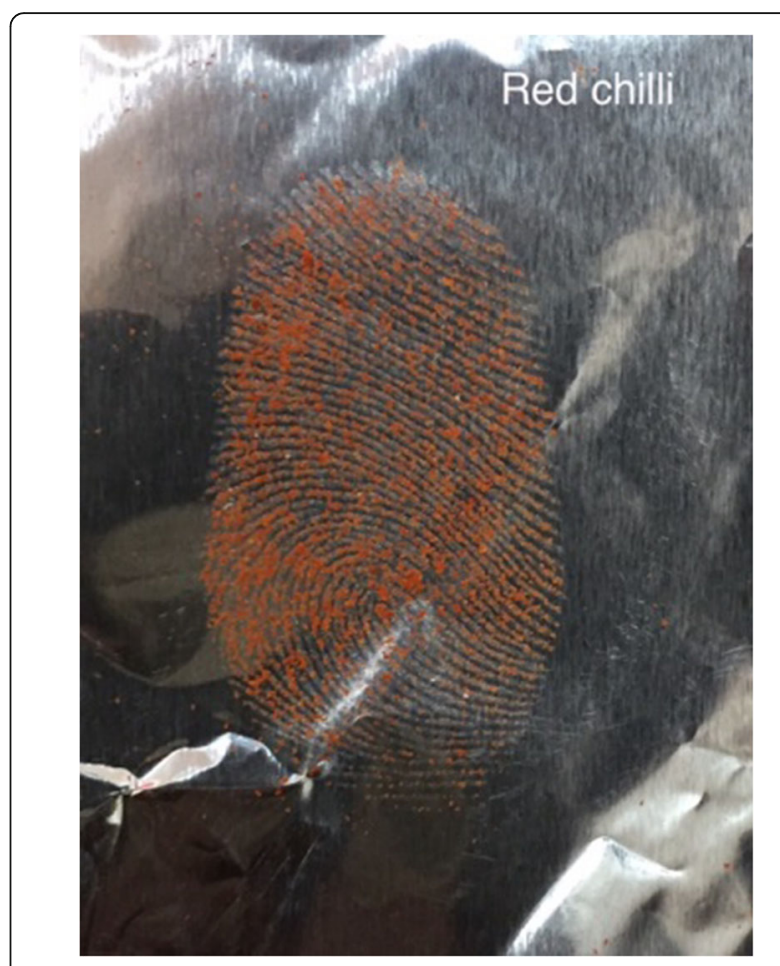

Fig. 13 Development of Latent fingerprint by Red Chilli powder on Aluminum Foil

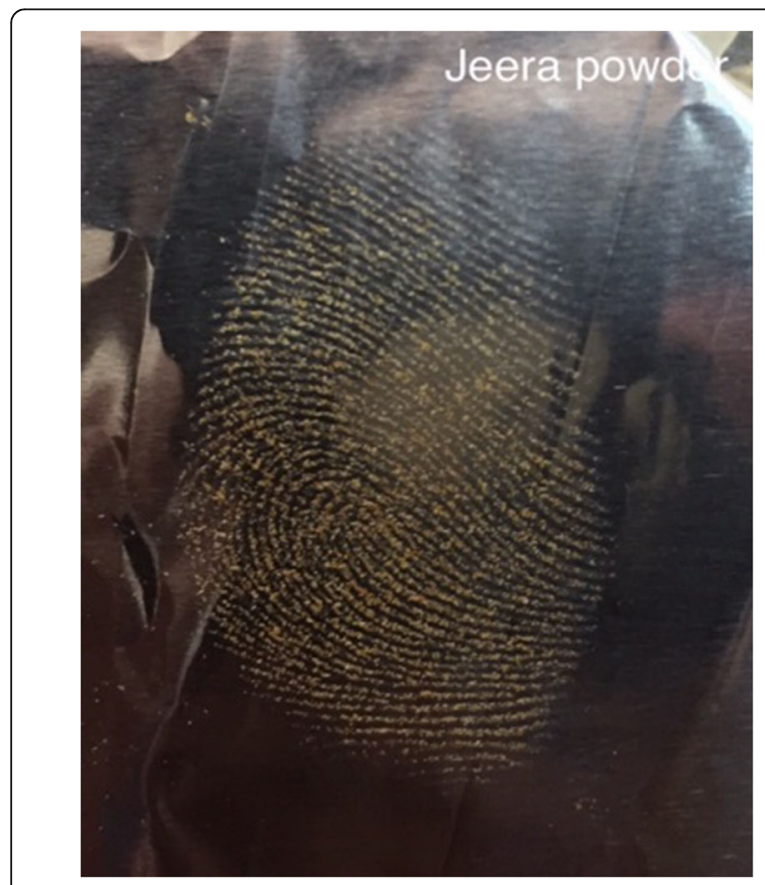

Fig. 12 Development of Latent fingerprint by Cumin powder on Aluminum Foil

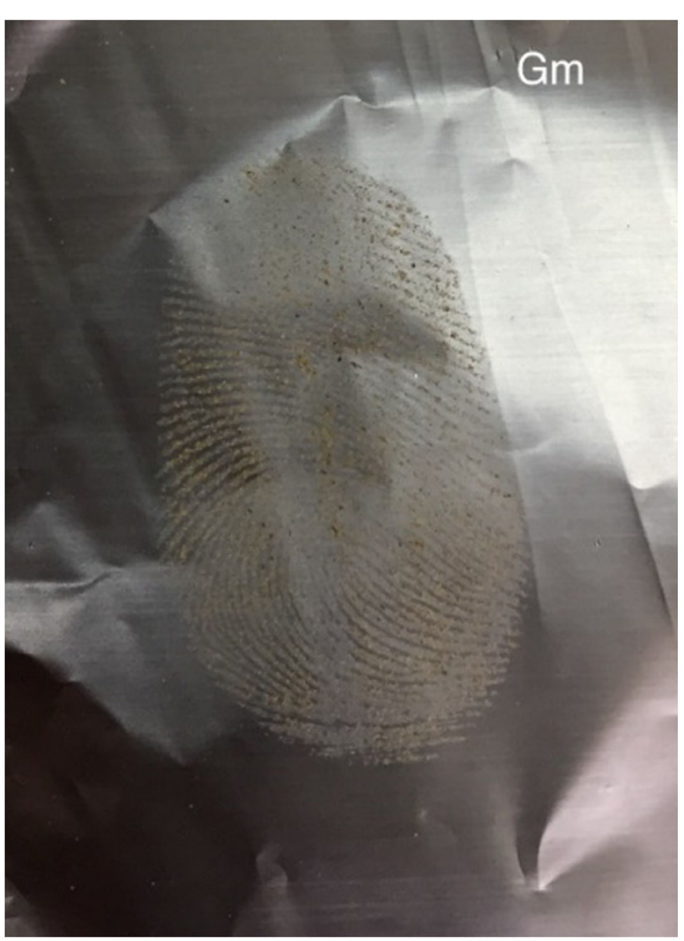

Fig. 14 Development of Latent fingerprint by Garam Masala powder on Aluminum Foil 


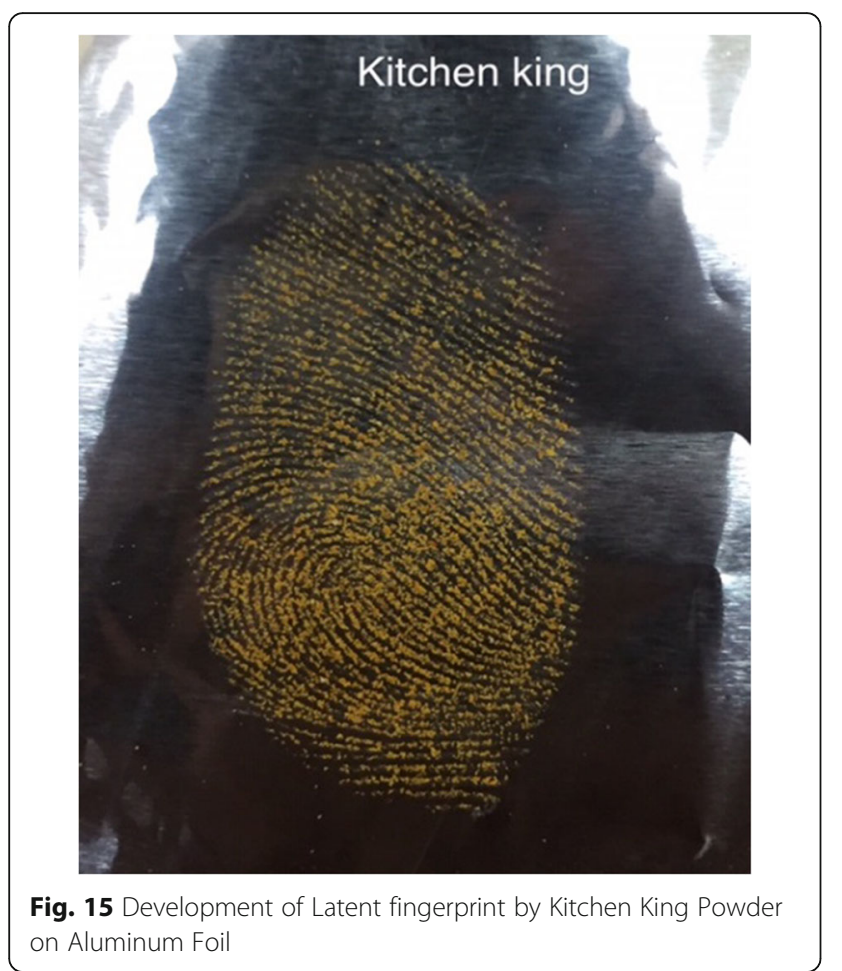

Fig. 15 Development of Latent fingerprint by Kitchen King Powder on Aluminum Foil

\section{Conclusion}

From the present study, it can be concluded that easily and commonly accessible and less expensive reagents i.e. , household kitchen powders could act as a beneficial substitute for decrypting the latent prints.

\section{Acknowledgements}

We are thankful to Dr. Manish Goswami Principal, UIAHS, Chandigarh University for his guidance, motivation and helping us all the time by his immense knowledge.

\section{Funding}

This study did not receive any type of funding.

\section{Availability of data and materials}

The datasets generated during and analyzed during the current study are available from the corresponding author on reasonable request.

\section{Authors' contributions}

$A D$ - Contributed in the study by developing content for the paper and result formation. SA- Contributed in collection and development of prints and result and discussion formation. Anjali A - Contributed in collection and development of prints and introduction formation. Abhishek A - Provided fingerprints for the study and also contributed in methodology formation. PV - Supervised the whole research and guided at every step. US-Supervised the complete research and helped in result formation. All authors read and approved the final manuscript.

\section{Ethics approval and consent to participate}

Written informed consent was obtained from all participants for this study.

\section{Consent for publication}

Written informed consent was obtained from the participants for the publication of this report and any accompanying images.

\section{Competing interests}

The authors declare that they have no competing interests.

\section{Publisher's Note}

Springer Nature remains neutral with regard to jurisdictional claims in published maps and institutional affiliations.

Received: 13 July 2017 Accepted: 26 March 2018

Published online: 06 April 2018

\section{References}

Crown DA (1969) The development of latent fingerprints with Ninhydrin. J Crim Law Criminol Police Science 60(2):258-264

Dalrymple BE, Duff Jo M, Menzel ER (1977) Inherent fingerprint luminescencedetection by laser. J of Forensic Sci 22(1):106-115

Garg RK (2011) A new technique for visualization of latent fingerprints on various surfaces using powder from turmeric. Egypt J Forensic Sci 1:53-57

Haque F, Westland AD, Kerr FM (1989) A small particle (iron oxide) suspension for detection of latent fingerprints on smooth surfaces. Forensic Sci Int 41(1):73-82

Jasuja OP, Kaur A, Kumar P (2012) Fixing latent fingermarks developed by iodine fuming: a new method. Forensic Sci Int 223(1-3):e47-e52

Kerr FM, Barron IW, Haque F, Westland AD (2013) Organic-Base fluorescent powders for latent fingerprint detection on smooth surfaces: part II. Canadian Soc of Forensic Sci J 16(1):39-44

Kumari H, Kaur R, Garg RK (2011) New visualizing agents for latent fingerprints: synthetic food and festival Colours. Egypt J of Forensic Sci 1(3-4):133-139

Pandey BP (2003) Spices and condiments economic botany, 6th edn. S. Chand and Company Limited, New Delhi, pp 289-290

Singh K, Sharma S, Garg RK (2013) Visualization of latent fingerprints using silica gel G: a new technique. Egypt J of Forensic Sci 3(1):20-25 